\title{
ANÁLISE DA UTILIZAÇÃO DE PAGAMENTOS MÓVEIS NO CONTEXTO BRASILEIRO: PERCEPÇÃO DE USUÁRIOS E NÃO USUÁRIOS
}

\author{
ANALYZING THE USE OF MOBILE PAYMENTS IN THE BRAZILIAN \\ CONTEXT: USERS AND NON-USERS'VIEWS
}

\author{
Gabriel Machado Braido ${ }^{1}$ \\ Amarolinda Zanela Klein ${ }^{2}$
}

Resumo: O objetivo deste artigo consistiu em analisar a percepção dos usuários e não usuários quanto à utilização de pagamentos móveis no Brasil. Os pagamentos móveis (mobile payments) podem ser definidos como pagamentos de bens, serviços e contas por meio de um dispositivo móvel, utilizando redes de comunicação sem fio. Analisando-se as pesquisas acadêmicas já realizadas sobre essa temática, não foi identificado estudo semelhante no Brasil até o momento, o que justifica a pesquisa. Para alcançar seu objetivo, o estudo adotou o método survey, com uma amostra de 580 pessoas. Os resultados obtidos, com a aplicação de questionário, fornecem dados para a compreensão da difusão da utilização de pagamentos móveis no contexto brasileiro a partir do ponto de vista de pessoas que realizam esses pagamentos e outras que, ainda, não os utilizam, apontando benefícios percebidos, bem como barreiras para a sua difusão no contexto nacional.

Palavras-chave: Pagamentos móveis. Tecnologias móveis. Difusão.

Abstract: This article aimed to analyze the perception of users and non-users of mobile payments in Brazil. The mobile payments can be defined as payments for goods, services and accounts through a mobile device, using wireless communication. Analyzing the academic research already developed on the topic, no similar study was identified in Brazil so far, which justifies the research. To answer and achieve its goal, the study adopted the survey method, on a sample of 580 people. The results obtained with the application of the questionnaire provide data for the understanding of the use of mobile payments' diffusion in the Brazilian context from the point of view of people who make these payments and others who do not yet use them, pointing to perceived benefits as well as barriers dissemination in the national context.

Keywords: Mobile payments. Mobile technologies. Difusion.

(5) 1 Doutor em Administração (Unisinos), Universidade do Vale do Taquari - Univates, Lajeado, Rio Grande do Sul, Brasil. gabrielb@univates.br

(1) ${ }^{2}$ Doutora em Administração (USP), Universidade do Vale do Rio dos Sinos - Unisinos, Porto Alegre, Rio Grande do Sul, Brasil. aczanela@ unisinos.br

\section{Cite como}

American Psychological Association (APA)

Braido, G. M., \& Klein, A. Z. (2020, jul./dez.). Análise da utilização de pagamentos móveis no contexto brasileiro: percepção de usuários e não usuários. Revista Inovação, Projetos e Tecnologias, São Paulo, 8(2), 235-254. https://doi.org/10.5585/iptec.v8i2.17639. 


\section{Introdução}

Este artigo aborda a percepção de usuários e não usuários de pagamentos móveis sobre a sua utilização no contexto brasileiro. Os pagamentos móveis (mobile payments) podem ser definidos como pagamentos de bens, serviços e contas por meio de um dispositivo móvel (como smartphones ou tablets, por exemplo), utilizando redes de comunicação sem fio (Dahlberg, Gou \& Ondrus, 2015).

A difusão dos pagamentos móveis está associada à rápida evolução das Tecnologias da Informação e Comunicação (TIC), que têm propiciado novas formas de organização de trabalho, novos modos de produção e de consumo, comunicação e novas relações com as informações (Braido \& Klein, 2016). Nesse contexto, as transações financeiras entre empresas e pessoas evoluíram de uma simples troca de papel-moeda para os pagamentos eletrônicos, com a utilização de cartões de crédito, via telefone e até mesmo por meio da internet (Martins, Santos, Di Serio, \& Martins, 2008).

A indústria de pagamentos experimenta a convergência de tecnologia para processamento de transações, e existem diversos benefícios reconhecidos para todos os participantes do setor, em que as diversas mudanças no comportamento dos consumidores parecem favorecer a adoção de novos métodos de pagamento ao redor do mundo (Dewan \& Chen, 2005). A utilização de sistemas de pagamentos móveis pode ser entendida como uma das inovações mais promissoras para o desenvolvimento da inclusão financeira devido ao crescimento das vendas de smartphones e à facilidade do uso de tecnologias móveis (Ricardo \& Freitas, 2015). Essa forma de pagamento tem sido um dos principais impulsionadores do desenvolvimento socioeconômico nos mercados emergentes. Fatores como os avanços na tecnologia, as condições socioeconômicas e a alta taxa de penetração de dispositivos móveis têm impulsionado o desenvolvimento dos pagamentos móveis nesses mercados.

O uso de meios eletrônicos de pagamento tem, aos poucos, ganhado espaço no Brasil. Em 2017, por exemplo, pela primeira vez, o volume de transações por cartão (crédito, débito ou pré-pago) superou o dinheiro físico, visto que a movimentação de cartões foi de $\mathrm{R} \$ 1,36$ trilhão contra $\mathrm{R}$ \$ 1,31 trilhão em saques, de acordo com levantamento da Associação Brasileira das Empresas de Cartões de Crédito e Serviços (Abecs). A Abecs, ainda, sugere que o pagamento móvel já é uma realidade no país, com a entrada da Apple Pay e Samsung Pay, e estima que, até o ano de 2030, as cédulas e moedas serão substituídas por pagamentos via celular (A revolução..., 2018). 
Frente a esse contexto, é importante compreender a percepção dos usuários e não usuários de pagamentos móveis no Brasil, a fim de identificar quais são os motivadores para utilização e quais são as barreiras enfrentadas nesse processo, a fim de possibilitar a proposição de estratégias que permitam a adoção e difusão desse meio de pagamento no País.

Analisando-se as pesquisas acadêmicas já realizadas sobre essa temática, não foi identificado estudo semelhante no Brasil até o momento. Portanto, justifica-se a realização desta pesquisa. Diante disso, o objetivo deste artigo consistiu em analisar a percepção dos usuários e não usuários quanto à utilização de pagamentos móveis no Brasil. Para alcançar o objetivo, a pesquisa adotou o método survey e a amostragem seguiu o critério de acessibilidade. Os resultados obtidos com a aplicação do questionário são apresentados na sequência (seção 4) e fornecem dados para a compreensão da difusão da utilização de pagamentos móveis brasileiro com base no ponto de vista de pessoas que realizam pagamentos móveis ou não.

O artigo está estruturado nesta seção introdutória e outras 5 seções, compreendendo os conceitos de pagamentos móveis (seção 2), procedimentos metodológicos (seção 3), apresentação e análise dos resultados (seção 4) e, por fim, as conclusões e recomendações do estudo (seção 5), seguidas das referências utilizadas.

\section{Pagamentos móveis}

Os pagamentos móveis (mobile payments) podem ser definidos como pagamentos efetuados ou habilitados por meio de tecnologias digitais de mobilidade, e de dispositivos portáteis, com ou sem o uso de redes de telecomunicações móveis (Diniz, Albuquerque \& Cernev, 2011). Para o Banco Central do Brasil (2010, p. 64), o pagamento móvel pode ser caracterizado como pagamento quando "[..] o cliente faz uso de um dispositivo móvel para iniciar, autorizar ou confirmar um pagamento diretamente com a contraparte, representando a convergência entre serviços bancários e telefônicos".

Os pagamentos móveis podem ser considerados um produto resultante do desenvolvimento de tecnologias móveis que oferecem soluções específicas ao setor bancário, consistindo em um método alternativo para o pagamento de mercadorias, serviços e outros (Wang, Putri, Christianto, \& Hutama, 2019). A tecnologia móvel, vista como um meio de pagamento ou canal bancário, tem o potencial de permitir que duas questões importantes sejam abordadas ao mesmo tempo: (1) em relação à demanda, representa uma oportunidade para a inclusão financeira de uma população que tem baixo acesso aos serviços bancários tradicionais; (2) em relação à oferta, abre possibilidade para as instituições financeiras oferecerem uma 
grande diversidade de serviços, a baixo custo, para uma grande variedade de clientes das camadas sociais mais pobres ou de localizações mais remotas (Diniz, Albuquerque \& Cernev, 2011).

Brandão (2011) complementa que, na definição dos pagamentos móveis, não consta a origem dos fundos para o pagamento realizado, visto que uma variedade de serviços de pagamento pode ser constituída via celular, como: via cartões de crédito ou débito de conta bancária; celular como carteira eletrônica, usado para transações off-line (normalmente para pagamentos de baixo valor), com autenticação imediata e por proximidade (como passagens em ônibus, metrôs e trens); e conta de cartão pré-pago operada via celular para transações de pagamento on-line.

Os pagamentos móveis têm recebido atenção crescente, de consumidores a comerciantes, pois se apresentam como alternativa ao uso de dinheiro, cheque ou cartões de crédito e débito (Oliveira, Thomas, Baptista, \& Campos, 2016). Contudo, embora tenha havido aumento constante na oferta e promoção desse tipo de pagamento, observa-se que a sua adoção, ainda, tem sido bastante lenta (Park et al., 2019), porém o seu potencial é enorme (Oliveira et al., 2016).

A solução para o êxito dos pagamentos móveis consiste na cooperação dos vários agentes dentro de um modelo colaborativo, já que os esforços individuais somente terão êxito limitado e local. As empresas e os bancos, que expressam o maior interesse nos pagamentos móveis, são essenciais para a proliferação e aceitação desses serviços pelos consumidores. Porém, como esta é, apenas, uma solução alternativa a outras formas de pagamento, o vendedor e o consumidor assumirão o papel principal em relação à difusão dessa tecnologia (Barbosa, 2010). O modelo de negócios mais viável de pagamentos móveis, de acordo com Agrawal (2009), é aquele que permite aos intervenientes focarem em seu negócio e, ao mesmo tempo, explorarem novos serviços que gerem novas receitas, satisfazendo às exigências e necessidades dos clientes, facilitando a retenção e reforçando a lealdade dos consumidores.

Chun (2019) ressalta que o principal benefício dos pagamentos móveis é que eles são mais convenientes e portáteis, e, embora essa modalidade de pagamento ainda seja considerada por alguns como insegura, muitos usuários acreditam que a conveniência oferecida supera o risco de segurança associado à sua utilização. Algumas pessoas, contudo, relutam em utilizar aplicativos de pagamento devido à inconveniência do download de aplicativos, da tela pequena do telefone e da possibilidade de perda ou roubo do dispositivo móvel (Chun, 2019).

Muito tem se falado das possíveis consequências dos pagamentos móveis à economia e aos consumidores, visto tratar-se de um novo serviço tecnológico que pode facilitar o cotidiano 
de compras de muitas pessoas e movimentar ainda mais a economia. Além dessas questões, também é preciso considerar que há um público em potencial que pode ser incluído, em longo prazo, nessas compras, como as pessoas que não possuem conta em banco, pois o pagamento por meio dos dispositivos móveis não precisa ser associado às instituições bancárias (Moretti, 2013).

Apresentada uma breve conceitualização de pagamentos móveis, na próxima seção, são descritos os procedimentos metodológicos utilizados na condução desta pesquisa.

\section{Procedimentos metodológicos}

Esta pesquisa foi realizada por meio da aplicação de um questionário (survey) com amostragem não probabilística, que seguiu o critério de acessibilidade, visto que a amostra foi acessada por meio de redes sociais, especialmente via facebook. O questionário aplicado foi previamente revisado e testado por um grupo de pesquisa de stricto sensu, composto por 17 pessoas da área de tecnologia e sistemas de informação e foi aplicado por meio de um link do Google Formulários, o qual foi compartilhado com a rede de contatos dos pesquisadores, solicitando-se que este fosse encaminhado aos seus conhecidos.

A fim de levantar informações tanto das pessoas que já realizaram pagamentos móveis quanto das pessoas que, ainda, não utilizaram esse meio de pagamento, o questionário foi estruturado em dois blocos, sendo um específico para usuários e outro para não usuários. Para facilitar e uniformizar a compreensão do termo "pagamentos móveis", logo após o respondente aceitar participar da pesquisa, o questionário apresentava uma definição do termo e exemplos ilustrativos, conforme Figura 1.

Figura 1 - Excerto do questionário de coleta de dados

PAGAMENTOS MÓVEIS - definição: pagamentos efetuados ou autorizados por meio de tecnologias móveis, dispositivos móveis com ou sem o uso de redes de telecomunicações móveis. Alguns exemplos de pagamentos móveis: pagamento de boletos via celular, pagamento de corridas utilizando aplicativos (Uber, Cabify etc.), pagamentos por aproximação (NFC), entre outros.

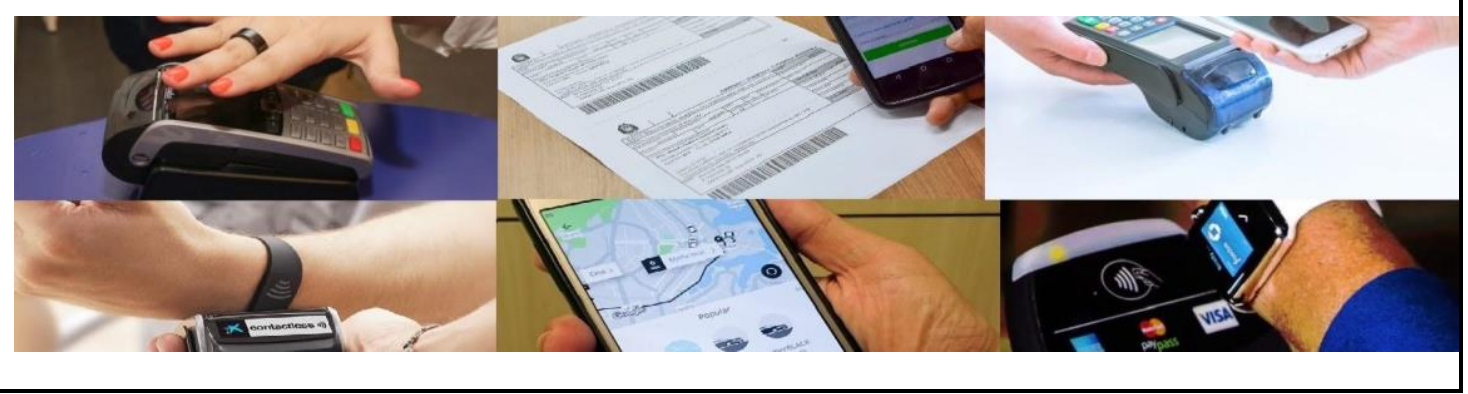

Fonte: Dados da pesquisa (2019). 
Logo abaixo desta Figura, foi apresentada a seguinte questão: "você já realizou algum tipo de pagamento utilizando dispositivos móveis (celular, smartphone, pulseira, anel ou relógio inteligente etc.) no Brasil?”. A partir dessa questão dicotômica, o respondente era direcionado a um conjunto de questões específicas, tanto abertas quanto fechadas, conforme Figura 2.

Figura 2 - Conjunto de questões do questionário de pesquisa

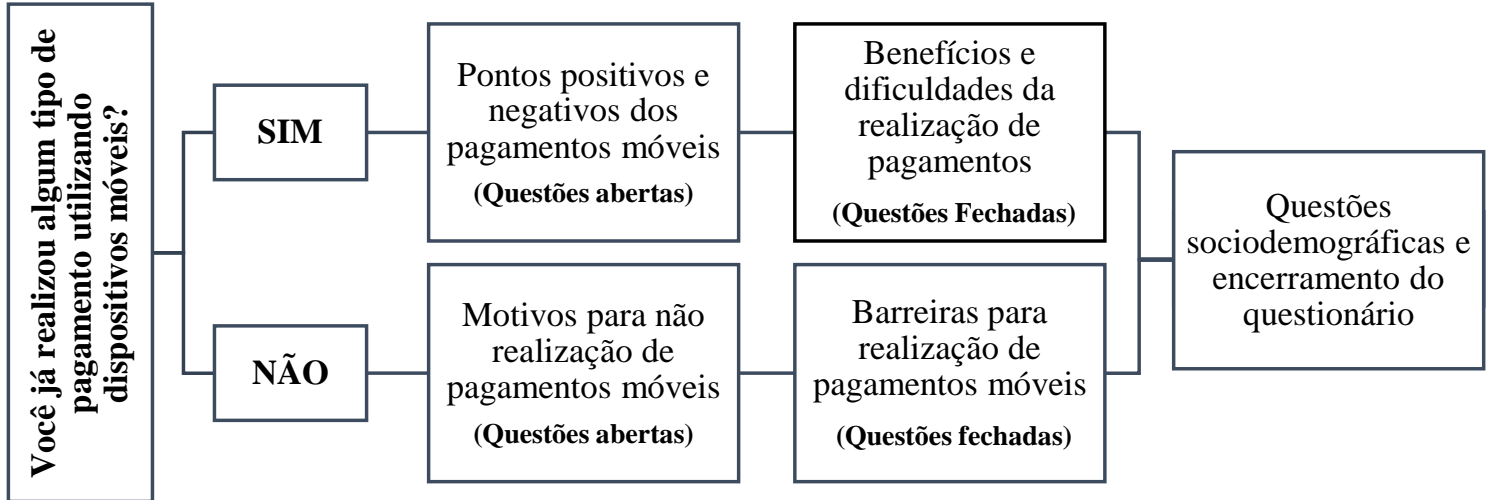

Fonte: Dados da pesquisa (2019).

Conforme Figura 2, ao responder "SIM" à questão inicial, o usuário era direcionado a um conjunto de questões abertas e fechadas sobre a sua realização de pagamentos móveis no Brasil; ao responder "NÃO", o respondente era direcionado a um conjunto de questões que buscava compreender os motivos para a não realização desse tipo de pagamentos e as barreiras identificadas. Por fim, todos os respondentes eram direcionados a um bloco de encerramento, contendo questões sociodemográficas. O questionário ficou disponível para preenchimento online entre os dias 09 de julho de 2018 e 12 de outubro de 2018, sendo respondido por 580 pessoas.

Como limitação do método, destaca-se a impossibilidade de generalização dos resultados obtidos, visto que a pesquisa se valeu da obtenção de uma amostra não probabilística e, por conveniência, fazendo com que os resultados sejam válidos, apenas, para essa amostra. Na próxima seção, os resultados da pesquisa são apresentados.

\section{Apresentação dos resultados}

Nesta seção são apresentados os resultados obtidos com a aplicação do questionário, primeiramente o perfil da amostra (4.1), dados sobre a utilização de pagamentos móveis no contexto brasileiro (4.2), motivos para a realização de pagamentos móveis (4.3) e, por fim, a 
percepção dos não usuários de pagamentos móveis sobre a não realização desses pagamentos (seção 4.4).

\subsection{Perfil da amostra}

A amostra é composta por 580 pessoas, sendo predominantemente do sexo feminino, com idade média de 36 anos e em sua grande maioria com ensino superior completo ou pósgraduação. Quase metade (46\%) dos respondentes está empregada no setor privado e recebe até 5 salários mínimos (Tabela 1).

Tabela 1 - Resumo das questões sociodemográficas

\begin{tabular}{|c|c|c|}
\hline Questão & Respondentes & Porcentagem \\
\hline \multicolumn{3}{|l|}{ Gênero } \\
\hline Masculino & 184 & $31,72 \%$ \\
\hline Feminino & 396 & $68,28 \%$ \\
\hline \multicolumn{3}{|l|}{ Grau de instrução } \\
\hline Ensino Fundamental & 4 & $0,69 \%$ \\
\hline Ensino Médio & 72 & $12,41 \%$ \\
\hline Ensino Superior & 184 & $31,72 \%$ \\
\hline Pós-Graduação & 320 & $55,17 \%$ \\
\hline \multicolumn{3}{|l|}{ Ocupação Principal } \\
\hline Empregado do Setor Privado & 270 & $46,55 \%$ \\
\hline Empregado do Setor Público & 125 & $21,55 \%$ \\
\hline Empresário & 74 & $12,76 \%$ \\
\hline Estudante & 63 & $10,86 \%$ \\
\hline Atualmente desempregado & 14 & $2,41 \%$ \\
\hline Aposentado/Pensionista & 34 & $5,86 \%$ \\
\hline \multicolumn{3}{|l|}{ Renda familiar } \\
\hline Até 2 salários mínimos & 61 & $10,52 \%$ \\
\hline De 3 até 5 salários mínimos & 213 & $36,72 \%$ \\
\hline De 6 a 10 salários mínimos & 164 & $28,28 \%$ \\
\hline Mais de 10 salários mínimos & 142 & $24,48 \%$ \\
\hline
\end{tabular}

Fonte: Dados da pesquisa (2019).

A Tabela 2 apresenta os resultados referentes ao tempo de uso da Internet pelo celular; a maioria dos respondentes a utiliza há, pelo menos, 5 anos. 
Tabela 2 - Tempo de uso da internet pelo celular

\begin{tabular}{cccc} 
Tempo de uso & Frequência & Porcentagem & $\begin{array}{c}\text { Porcentagem } \\
\text { Acumulada }\end{array}$ \\
Menos de um ano & 6 & $1,03 \%$ & $1,03 \%$ \\
De 1 a 2 anos & 39 & $6,72 \%$ & $7,76 \%$ \\
De 3 a 4 anos & 115 & $19,83 \%$ & $27,59 \%$ \\
De 5 a 6 anos & 176 & $30,34 \%$ & $57,93 \%$ \\
7 anos ou mais & 243 & $41,90 \%$ & $99,83 \%$ \\
Não utilizo & 1 & $0,17 \%$ & $100,00 \%$ \\
Total & $\mathbf{5 8 0}$ & $\mathbf{1 0 0 , 0 0 \%}$ & \\
\hline
\end{tabular}

Fonte: Dados da pesquisa (2019).

\subsection{Realização de pagamentos móveis no contexto brasileiro}

A fim de facilitar a compreensão do termo "pagamentos móveis" e uniformizar o entendimento da questão, conforme já foi explicado, o questionário apresentava uma definição do termo e exemplos de pagamentos móveis, ilustrados com imagens, conforme apresentado na Figura 1. Logo abaixo dessa Figura, foi apresentada a seguinte questão: "você já realizou algum tipo de pagamento utilizando dispositivos móveis (celular, smartphone, pulseira, anel ou relógio inteligente, etc.) no Brasil?" O resultado demonstra que 495 respondentes, $85,3 \%$ da amostra, já utilizaram algum dispositivo móvel para realização de pagamentos no Brasil, enquanto somente 85 pessoas, $14,7 \%$ dos respondentes, ainda não utilizaram.

A partir dessa pergunta inicial, os usuários de pagamentos móveis foram conduzidos a um conjunto de questões para investigar aspectos relativos à utilização desses pagamentos, apresentados a seguir, bem como facilitadores e barreiras para sua adoção no Brasil (seção 4), enquanto os respondentes que não utilizam pagamentos móveis foram conduzidos para questões que buscaram identificar os fatores para a não realização desse tipo de pagamentos (seção 5). Inicialmente, questionou-se aos usuários de pagamentos móveis há quanto tempo eles os utilizam (Tabela 3). 
Tabela 3 - Tempo que realiza pagamentos móveis

\begin{tabular}{lccc} 
Tempo de uso & Frequência & Porcentagem & $\begin{array}{c}\text { Porcentagem } \\
\text { Acumulada }\end{array}$ \\
Menos de 1 ano & 54 & $10,91 \%$ & $10,91 \%$ \\
De 1 a 2 anos & 166 & $33,54 \%$ & $44,44 \%$ \\
De 3 a 4 anos & 156 & $31,52 \%$ & $75,96 \%$ \\
De 5 a 6 anos & 68 & $13,74 \%$ & $89,70 \%$ \\
Mais de 7 anos & 51 & $10,30 \%$ & $100,00 \%$ \\
Total & $\mathbf{4 9 5}$ & $\mathbf{1 0 0 , 0 0 \%}$ & \\
\hline
\end{tabular}

Fonte: Dados da pesquisa (2019).

Os resultados apontam que a maior parte dos respondentes utiliza pagamentos móveis há, no máximo, 4 anos. Somente cerca de 23\% utilizam há, pelo menos, 5 anos. No que se refere à frequência de realização (Tabela 4), observa-se que quase a metade $(43,84 \%)$ dos usuários realizam pagamentos móveis semanalmente e $42,02 \%$ os realizam mensalmente. Constata-se que esse meio de pagamento, ainda, não faz parte do comportamento diário das pessoas, visto que apenas 9,49\% dos respondentes afirma realizar pagamentos móveis diariamente.

Tabela 4 - Frequência de realização de pagamentos móveis

\begin{tabular}{cccc} 
Frequência de pagamentos & Frequência & Porcentagem & $\begin{array}{c}\text { Porcentagem } \\
\text { Acumulada }\end{array}$ \\
Diariamente & 47 & $9,49 \%$ & $9,49 \%$ \\
Semanalmente & 217 & $43,84 \%$ & $53,33 \%$ \\
Mensalmente & 208 & $42,02 \%$ & $95,35 \%$ \\
Semestralmente & 19 & $3,84 \%$ & $99,19 \%$ \\
Anualmente & 4 & $0,81 \%$ & $100,00 \%$ \\
& $\mathbf{4 9 5}$ & $\mathbf{1 0 0 , 0 0 \%}$ & \\
\hline
\end{tabular}

Fonte: Dados da pesquisa (2019).

Os meios utilizados para a realização de pagamentos móveis podem ser visualizados na Tabela 5. O smartphone, seja para pagamentos via app ou web, é o meio mais utilizado $(66,90 \%)$ seguido do pagamento por aproximação/NFC $(15,59 \%)$. 
Tabela 5 - Dispositivos utilizados para realização de pagamentos

\begin{tabular}{|c|c|c|c|}
\hline Dispositivo utilizado* & Frequência & Porcentagem & $\begin{array}{l}\text { Porcentagem } \\
\text { Acumulada }\end{array}$ \\
\hline $\begin{array}{l}\text { Pagamento utilizando o smartphone (via } \\
\text { app ou web) }\end{array}$ & 485 & $66,90 \%$ & $66,90 \%$ \\
\hline $\begin{array}{l}\text { Pagamento por aproximação (NFC) } \\
\text { utilizando smartphone }\end{array}$ & 113 & $15,59 \%$ & $82,48 \%$ \\
\hline $\begin{array}{l}\text { Pagamento utilizando tablet (via app ou } \\
\text { web) }\end{array}$ & 112 & $15,45 \%$ & $97,93 \%$ \\
\hline Pagamento utilizando relógio inteligente & 9 & $1,24 \%$ & $99,17 \%$ \\
\hline $\begin{array}{l}\text { Pagamento por aproximação (NFC) } \\
\text { utilizando pulseira ou anel de pagamento }\end{array}$ & 6 & $0,83 \%$ & $100,00 \%$ \\
\hline & 725 & $100,00 \%$ & \\
\hline
\end{tabular}

Fonte: Dados da pesquisa (2019). * Questão de múltipla escolha.

Os tipos de produtos e serviços pagos de forma móvel são demonstrados na Tabela 6.

Tabela 6 - Produtos e/ou serviços pagos com dispositivos móveis

$\begin{array}{lcc}\text { O que já foi pago* } & \text { Frequência } & \text { Porcentagem } \\ \text { Boletos } & 463 & 93,54 \% \\ \text { Transferência de dinheiro para pessoa física } & 431 & 87,07 \% \\ \text { Pagamento de serviços básicos (água, luz, telefone etc.) } & 375 & 75,76 \% \\ \text { Serviços de transporte privado (Uber, Cabify, Cias aéreas etc.) } & 334 & 67,47 \% \\ \text { Recarga de celular } & 260 & 52,53 \% \\ \text { Alimentação (iFood, Pedidos Já etc.) } & 257 & 51,92 \% \\ \text { Provedores de serviços online (Spotify, Netflix, etc.) } & 248 & 50,10 \% \\ \text { Atividades de lazer (parques, shows, festas, esportes, viagens } & & \\ \text { etc.) } & 247 & 49,90 \% \\ \text { Impostos e/ou serviços de governo } & 207 & 41,82 \% \\ \text { Transferência de dinheiro para pessoa jurídica } & 206 & 41,62 \% \\ \text { Serviços de transporte público } & 41 & 8,28 \% \\ \text { Combustível } & 3 & 0,61 \% \\ \text { Criptomoedas } & 1 & 0,20 \%\end{array}$

Fonte: Dados da pesquisa (2019). * Questão de múltipla escolha.

Há variedade de produtos ou serviços pagos de forma móvel, destacando-se o pagamento de boletos, transferências para pessoas físicas e pagamentos de serviços básicos. Vale ressaltar que o uso da mobilidade para o pagamento de transporte público, embora seja realidade em diversos países, ainda tem baixa utilização no Brasil, sendo destacada por, apenas, $8,28 \%$ dos respondentes. 


\subsection{Motivos para a realização de pagamentos móveis}

Uma série de benefícios foram pontuados pelos usuários como motivadores para a realização de pagamentos móveis. (Tabela 7).

Tabela 7 - Benefícios percebidos nos pagamentos móveis no Brasil

$\begin{array}{lcc}\text { Benefício percebido* } & \text { Frequência } & \text { Porcentagem } \\ \text { Praticidade, comodidade } & 489 & 98,79 \% \\ \text { Rapidez, ganho de tempo } & 466 & 94,14 \% \\ \text { Mobilidade (pagamento em qualquer lugar) } & 452 & 91,31 \% \\ \text { Possibilidade de realizar pagamentos a qualquer momento } & 415 & 83,84 \% \\ \text { Facilidade de uso dos aplicativos/sistemas } & 303 & 61,21 \% \\ \text { Dispensa carregar outros objetos (ex.: carteira) } & 172 & 34,75 \% \\ \text { Segurança das operações } & 147 & 29,70 \% \\ \text { Menor custo dos serviços de pagamento } & 136 & 27,47 \%\end{array}$

Fonte: Dados da pesquisa (2019). * Questão de múltipla escolha.

A praticidade e comodidade são quase consenso entre os respondentes, seguidas da rapidez e mobilidade (possibilidade de realizar pagamentos em qualquer lugar e também a qualquer momento). Os resultados obtidos a partir de uma questão aberta, que possibilitava ao respondente relatar os pontos positivos dos pagamentos móveis, vão ao encontro dos dados da Tabela 7, por exemplo:

Praticidade: maior flexibilidade de horários para pagamento, não há preocupação em ter ou receber troco.

Praticidade de poder efetuar pagamentos onde estiver e independente do horário.

[...] não precisar levar dinheiro vivo e receber trocos em moedas [...]

Num futuro não tão distante, andar com carteira será dispensável, pois teremos tudo no celular, inclusive os cartões de débito, crédito e afins.

Praticidade: evita receber moedas de troco e até mesmo perder o dinheiro.

Outros aspectos positivos destacados são: não precisar ir até uma agência bancária ou casa lotérica para realizar pagamentos, evitando filas:

Realizar pagamentos por dispositivos é muito prático e fácil. Agiliza bastante nossos afazeres. Imagina, só de não precisar ir até um banco, achar estacionamento, pegar uma fila... Viva os dispositivos móveis!

Agilidade por poder pagar em qualquer dia e em qualquer lugar sem perder tempo em filas, podendo fazer em no máximo de 2 minutos o que fiz em um banco em 1 h. (No caso perdi todo o intervalo do almoço e voltei correndo pro serviço).

Por fim, aspectos relacionados à segurança, por não precisar carregar dinheiro consigo, e à facilidade de controlar os gastos mensais, devido aos aplicativos concentrarem os recibos e registros de compras, também foram destacados: 
Ter um controle maior sobre os gastos [...] os recibos já ficam salvos todos no dispositivo sem precisar guardar os papéis etc.

Ter as despesas registradas para controle do orçamento;

Sensação de segurança: por não ser necessário circular com dinheiro ou ir a agências bancárias.

Controle: os aplicativos de finanças pessoais integram com as informações da conta bancária e fazem lançamentos automáticos e alocação no plano de contas de acordo com o nome de cada estabelecimento, enquanto os pagamentos em dinheiro precisam ser lançados manualmente um a um

Segurança (assalto para roubar o dinheiro).

A pesquisa investigou, também, as principais dificuldades percebidas pelos usuários na realização de pagamentos móveis (Tabela 8). Ao contrário dos benefícios percebidos, as dificuldades para realização de pagamentos móveis não apresentam números tão expressivos, contudo apresentam possibilidades de melhoria nas operações para as empresas ofertantes de soluções de pagamentos móveis no contexto brasileiro.

Tabela 8 - Dificuldades percebidas na realização de pagamentos móveis no Brasil

Dificuldades para realização de pagamentos móveis*

Problemas de conexão (ex.: falta de acesso à internet, internet lenta)

Falta de segurança dos sistemas para pagamentos móveis

Algumas instituições não oferecem esta possibilidade

Risco de perda ou roubo de dispositivos móveis

Os sistemas ou aplicativos às vezes ficam indisponíveis

Falta de padronização das soluções de pagamentos móveis

Burocracia para ativação dos sistemas de pagamentos móveis

Alto custo de conexão de internet móvel

Falta de conhecimento sobre essa forma de pagamento

Não identifico nenhum ponto negativo

Os sistemas ou aplicativos são difíceis de utilizar

Alto custo dos dispositivos usados para pagamentos móveis

Tarifas cobradas pelos operadores
Frequência

299

262

188

183

153

89

88

58

41

35

21

21

1
Porcentagem

$60,40 \%$

$52,93 \%$

$37,98 \%$

$36,97 \%$

$30,91 \%$

$17,98 \%$

$17,78 \%$

$11,72 \%$

$8,28 \%$

$7,07 \%$

$4,24 \%$

$4,24 \%$

$0,20 \%$

Fonte: Dados da pesquisa (2019).* Questão de múltipla escolha.

A principal dificuldade refere-se aos problemas de conexão, como a falta de acesso à Internet ou Internet lenta e, na sequência, está a falta de segurança dos sistemas para pagamentos móveis, questão que precisa ser esclarecida junto aos usuários. A fidelidade às instituições tradicionais de pagamento também parece ser valorizada para a escolha de soluções de pagamentos móveis, visto que 37,98\% dos respondentes afirmam que algumas instituições, 
ainda, não oferecem esse tipo de solução, referindo-se, possivelmente, às instituições com as quais já trabalham. Outros $36,97 \%$ dos respondentes alegam ter medo da perda ou roubo dos dispositivos móveis.

Foi também apresentada uma questão aberta para que os respondentes destacassem os pontos negativos dos pagamentos móveis no contexto brasileiro. As respostas foram ao encontro do observado na Tabela 10, visto que os respondentes relataram, prioritariamente, seus anseios quanto à falta de segurança nas operações e do sigilo das informações, dificuldades de conexão à Internet e indisponibilidade de rede, por exemplo:

Dificuldades de acesso à Internet e dificuldade de manusear o aparelho (tela pequena, teclado etc.)

Em alguns lugares o sinal ruim da internet faz com que uma coisa simples se torne uma dor de cabeça.

Nem sempre o sinal de Internet é muito bom, o que dificulta o pagamento.

Quanto à segurança, os respondentes afirmaram:

não creio que haja pontos negativos, mas acredito que haja pontos de atenção, com muita mobilidade, abre muita brecha para as fraudes, se o banco ou instituição financeira não tiver muita eficiência de entrega o cliente pode ser prejudicado com possiveis fraudes.

Redes não seguras, expondo dados pessoais do usuário

Vazamento de informação

O risco de ter seu celular roubado (por exemplo) e com ele irem todos seus dados já précadastrados em aplicativos.

Outro aspecto que merece atenção diz respeito à atualização dos equipamentos para a realização de pagamentos, como as máquinas de cartão, por exemplo. Devido ao Brasil ser um país de tamanho continental, a substituição e instalação de máquinas modernas em todos os pontos de venda acaba sendo prejudicada, o que tem causado alguns transtornos na realização de pagamentos, conforme o relato a seguir:

algumas máquinas POS (ponto de venda) não estão atualizadas para receber do cliente por tecnologia de aproximação. Solicitam os 4 últimos dígitos, código de segurança, senha, e torna o pagamento chato e complicado. Algumas máquinas atuais é só aproximar e o pagamento já finaliza, sem necessidade de usar a senha.

Um usuário relatou, ainda, a dificuldade em obter o dinheiro de volta no caso de cobrança indevida em serviços de transporte, algo que, se fosse pago com meios mais tradicionais, não teria acontecido:

não vejo muitos pontos negativos, mas poderia citar algumas cobranças indevidas que tive com serviços de transporte, onde houve demora e incomodação para conseguir resgatar o valor. Nesse caso específico o pagamento móvel ao invés de facilitar acaba gerando transtornos que não existiriam se o pagamento fosse feito na forma tradicional.

Vale ressaltar, ainda, que outros respondentes afirmam que não há aspectos negativos nesse tipo de transação e acreditam que este seja o futuro das transações financeiras, o que pode 
ser resumido neste relato: "acredito que não há (pontos negativos). É um processo evolutivo sem volta."

Solicitou-se aos usuários que avaliassem a quantidade de soluções de pagamentos oferecidas no Brasil. Observa-se, na Tabela 9, que não há consenso quanto a essa questão. Cerca de $25 \%$ dos respondentes afirmaram não conseguir avaliar a quantidade de soluções oferecidas.

Tabela 9 - Avaliação da quantidade de oferta de soluções de pagamentos móveis

$\begin{array}{lcc}\text { Quantidade de soluções de pagamentos } & \text { Frequência } & \text { Porcentagem } \\ \text { Quantidade adequada } & 167 & 33,74 \% \\ \text { Faltam opções (poucos fornecedores) } & 153 & 30,91 \% \\ \text { Há muitas opções (muitos fornecedores) } & 52 & 10,51 \% \\ \text { Não consigo avaliar } & 123 & 24,85 \% \\ \text { Total } & \mathbf{4 9 5} & \mathbf{1 0 0 , 0 0 \%}\end{array}$

Fonte: Dados da pesquisa (2019).

Em um espaço aberto para o registro de suas percepções, dois usuários manifestaram as seguintes opiniões:

"ainda há um vínculo muito forte às instituições físicas. Então acredito que isso não conta, pois as instituições com as quais eu trabalho disponibilizam o serviço. $O$ que falta são opções como o NuBank, onde o relacionamento é completamente virtual."

"Quanto mais, melhor. Pode melhorar a oferta."

Na próxima seção, são apresentados os resultados da pesquisa realizada com os não usuários de pagamentos móveis.

\subsection{Percepção de não usuários de pagamentos móveis}

Inicialmente, questionou-se, de forma aberta, aos 85 respondentes que afirmaram nunca ter realizado pagamentos móveis, o(s) motivo(s) para isso. Os resultados apontam, principalmente, fatores relacionados à segurança (medo de ter dados sigilosos vazados, contas invadidas, saques indevidos etc.), dificuldade em manusear dispositivos móveis, falta de dispositivo adequado ou de capacidade de armazenamento para instalação de aplicativo. Algumas observações apresentadas pelos respondentes são apresentadas a seguir:

por não ter experiência com esse tipo de pagamento, acho o modo convencional mais simples.

Receio, medo de entrarem nas contas bancárias particulares. Situações problemas de descobrirem senhas e sacar dinheiro de contas.

Não tenho celular adequado. 
Do mesmo modo, os respondentes foram questionados se percebem algum possível benefício da utilização de pagamentos móveis; os principais destacados foram a agilidade, comodidade, praticidade, segurança (especialmente em relação a evitar assaltos), possibilidade de fazer os pagamentos a qualquer hora e em qualquer lugar. Os excertos a seguir corroboram essas afirmações:

facilidade de pagamento, rapidez, menor uso de papel moeda.

Acredito que seja muito mais prático e mais rápido, caso a pessoa já esteja acostumada.

Sim, são práticos, e facilita muito a vida de quem tem uma vida corrida.

Facilidade, poder sair de casa sem carteira.

Rapidez e fuga das filas e do péssimo atendimento da maioria dos bancos.

Claro, a praticidade, que parece ser o bem mais bem preservado atualmente.

Embora vários aspectos positivos tenham sido destacados, ressalta-se, também, que esse tipo de pagamento ainda enfrenta uma certa resistência por parte dos usuários, que, embora reconheçam os benefícios da tecnologia, ainda, preferem não utilizá-la, conforme relatado por esses dois respondentes:

benefícios sempre tem, mas a desconfiança é maior e, em caso de dúvida, melhor não realizar.

Sim, facilita, não precisa sair de casa para efetuar pagamentos e outros, mas não uso essa tecnologia.

Na sequência, solicitou-se que os respondentes indicassem as barreiras que os impedem de realizar os pagamentos móveis, podendo assinalar quantas opções desejassem (Tabela 10).

A principal barreira diz respeito à falta de segurança dos sistemas de pagamento, ou seja, as pessoas, em geral, desconfiam nos sistemas de pagamento e não se sentem seguras para realizar transações via dispositivos móveis, seguido pelo risco de perda ou roubo de dispositivos móveis e a falta de conhecimento sobre essa forma de pagamentos. Observa-se que esses resultados vão ao encontro da questão aberta apresentada anteriormente. Outras barreiras que merecem atenção dizem respeito aos problemas de conexão — falta de acesso à internet ou internet lenta, burocracia para ativação dos sistemas de pagamento e a não oferta dessa modalidade por algumas instituições. 
Tabela 10 - Barreiras para a realização de pagamentos móveis

\section{Barreira para realização}

Falta de segurança dos sistemas para pagamentos móveis

Risco de perda ou roubo de dispositivos móveis

Falta de conhecimento sobre esta forma de pagamentos

Problemas de conexão (falta de acesso à internet, internet lenta, etc.)

Burocracia para ativação dos sistemas de pagamentos

Algumas instituições não oferecem esta possibilidade

Os sistemas ou aplicativos às vezes ficam indisponíveis

Falta de padronização na oferta de soluções de

pagamentos móveis

Alto custo de conexão de internet móvel

Alto custo dos dispositivos usados para pagamentos

móveis

Os sistemas ou aplicativos são difíceis de utilizar

Não identifico nenhum ponto negativo

\section{Frequência}

52

46

44

27

24

21

18

15

10

5

5

\section{Porcentagem}

$61,18 \%$

$54,12 \%$

$51,76 \%$

$31,76 \%$

$28,24 \%$

$24,71 \%$

$21,18 \%$

$17,65 \%$

$11,76 \%$

$5,88 \%$

$5,88 \%$

Fonte: Dados da pesquisa (2019). * Questão de múltipla escolha.

É interessante, ainda, comparar as barreiras percebidas pelos usuários e pelos não usuários de pagamentos móveis - Tabela 11.

Tabela 11 - Barreiras percebidas por usuários versus não usuários

Barreiras percebidas

Não usuários

Problemas de conexão (falta de acesso à internet, internet lenta, etc.)

$60,40 \%$

$31,76 \%$

Falta de segurança dos sistemas para pagamentos móveis

$52,93 \%$

$61,18 \%$

Algumas instituições não oferecem esta possibilidade

$37,98 \%$

$24,71 \%$

Risco de perda ou roubo de dispositivos móveis

$36,97 \%$

$54,12 \%$

Os sistemas ou aplicativos às vezes ficam indisponíveis

$30,91 \%$

$21,18 \%$

Falta de padronização das soluções de pagamentos móveis

Burocracia para ativação dos sistemas de pagamentos móveis

$17,78 \%$

$28,24 \%$

Alto custo de conexão de Internet móvel

$11,72 \%$

$11,76 \%$

Falta de conhecimento sobre essa forma de pagamento

Não identifico nenhum ponto negativo

$7,07 \%$

$5,88 \%$

Os sistemas ou aplicativos são difíceis de utilizar

Alto custo dos dispositivos usados para pagamentos móveis

Tarifas cobradas pelos operadores

$0,20 \%$

$0,00 \%$

Fonte: Dados da pesquisa (2019). 
A falta de segurança dos sistemas de pagamento e o risco de perda ou roubo de dispositivos móveis foi destacada por uma parte considerável dos respondentes em ambos os grupos, o que requer a atenção das empresas ofertantes de soluções de pagamentos móveis.

Em uma última questão, solicitou-se aos respondentes não usuários que, se possível, avaliassem a quantidade de soluções de pagamentos móveis ofertadas no Brasil. A Tabela 12 demonstra que $60 \%$ disseram ser incapazes de avaliar a oferta, mas quase $30 \%$ afirmaram faltar opções.

Tabela 12 - Avaliação da quantidade de soluções de pagamentos móveis

\begin{tabular}{lcc}
\hline Quantidade de soluções de pagamentos & Frequência & Porcentagem \\
\hline Quantidade adequada & 5 & $5,88 \%$ \\
Faltam opções (poucos fornecedores) & 23 & $27,06 \%$ \\
Há muitas opções (muitos fornecedores) & 6 & $7,06 \%$ \\
Não consigo avaliar & 51 & $60,00 \%$ \\
\hline Total & $\mathbf{8 5}$ & $\mathbf{1 0 0 , 0 0 \%}$ \\
\hline
\end{tabular}

Fonte: Dados da pesquisa (2019).

No espaço aberto para o registro de outras observações a respeito da quantidade de soluções de pagamento oferecidas no Brasil, um respondente considerou que "faltam serviços que sejam honestos com o público e explicitem exatamente o que estão retendo, como, onde, até quando e por quê. Se não for código livre, nem adianta sonhar."

Apresentados os resultados obtidos com a realização desta pesquisa, na próxima seção, o estudo é concluído e são recomendadas ações visando à expansão da utilização de pagamentos móveis no Brasil.

\section{Conclusões e recomendações}

Os dados da pesquisa sugerem que a realização de pagamentos móveis no Brasil parece estar evoluindo, dado o expressivo número de pessoas que informaram já ter realizado esse tipo de transação no país. Contudo, os resultados, também, apontam para a necessidade de reflexão sobre alguns aspectos e de proposição de estratégias, tanto por parte das empresas ofertantes de soluções de pagamentos móveis quanto por parte do governo, a fim de facilitar o acesso e garantir a difusão dessa modalidade de pagamento por todo o território brasileiro.

Observa-se que vários aspectos subjetivos têm sido considerados pelos usuários de pagamentos móveis para optarem por esse tipo de serviço, como a praticidade, facilidade e a comodidade das transações, rapidez e ganho de tempo, mobilidade e possibilidade de realizar pagamentos a qualquer momento, em qualquer lugar. Contudo, o relato dos usuários e não 
usuários de pagamentos móveis evidencia a percepção de insegurança quanto à realização de pagamentos em meio digital. Esses dados corroboram a literatura recente. Como foi apresentado anteriormente, Chun (2019) ressalta que o principal benefício dos pagamentos móveis referese ao fato de que eles são mais convenientes, mas há, ainda, há relutância em utilizá-los devido a temores com questões de segurança.

A pesquisa realizada oferece subsídios para a ação gerencial, visto que ressalta alguns aspectos que necessitam reflexão e atenção por parte dos players de mercado. Um deles é a necessidade do estabelecimento de políticas públicas que facilitem o acesso à Internet em todo o território nacional. Isso é fundamental porque, conforme já foi abordado, a difusão dos pagamentos móveis representa uma oportunidade para a inclusão financeira de parte da população que não tem acesso a serviços bancários, por exemplo, pessoas que habitam regiões remotas (Diniz, Albuquerque \& Cernev, 2011).

Além disso, os dados apontam para a necessidade de um maior detalhamento e clareza nas questões relativas à segurança envolvida nas operações de pagamentos móveis; necessidade de maior divulgação e promoção dos serviços de pagamentos móveis ofertados no Brasil; maior divulgação dos pontos positivos dos pagamentos móveis, enfatizando a sua comodidade e a facilidade de realizar transações.

Por fim, destaca-se que este estudo apresenta como limitação o fato de considerar uma amostragem não probabilística e obtida por conveniência, não sendo permitido generalizar os resultados obtidos para toda a população brasileira. Contudo, mesmo o resultado sendo válido, apenas, para a amostra investigada, entende-se que a pesquisa fornece informações que podem ser úteis ao futuro estabelecimento de políticas públicas e de estratégias gerenciais que visem a mitigação das barreiras aqui identificadas, a fim de possibilitar uma maior difusão da utilização dos pagamentos móveis no Brasil. Recomenda-se que, para isso, novas pesquisas futuras sobre o tema sejam realizadas no País, tanto considerando-se o lado da demanda quanto da oferta de serviços dessa natureza.

\section{Referências}

Associação Brasileira das Empresas de Cartões de Crédito e Serviços - Abecs. (2018). A Revolução dos pagamentos: da moeda ao smartphone. Disponível em: https://www.abecs.org.br/noticia/a-revolucao-dos-pagamentos-da-moeda-ao-smartphone. Acesso em 24 fev. 2019.

Agrawal, M. Mobile Payments Business Models. (2009). Telecom Circle. Disponível em http://www.telecomcircle.com/2009/03/mobile- payments-business-models/. Acesso em 21 jul 2015. 
Banco Central do Brasil. (2010). Relatório de Inclusão Financeira. Disponível em http://www.bcb.gov.br/Nor/relincfin/relatorio_inclusao_financeira.pdf. Acesso em 20 jul. 2015.

Barbosa, P. M. M. da R. (2010). Perspectiva de evolução e potencialidade do NFC mpayment. Dissertação (Mestrado) - Mestrado em Inovação e Empreendedorismo Tecnológico, Faculdade de Engenharia da Universidade do Porto, Porto.

Braido, G. M. \& Klein, A. Z. (2016). Mobile payment: uma revisão sistemática da literatura. Estudo \& Debate, v. 23, n. 1, p. 192-216.

Brandão, A. J. L. (2011). Perspectivas para os celulares dos pobres servirem a políticas de inclusão financeira e de governo eletrônico: a proposição do Ministério de

Desenvolvimento Social no Governo Lula. In: XXXV Encontro da Associação Nacional dos Cursos de Pós-Graduação em Administração, 2011, Rio de Janeiro, RJ. Anais... Rio de Janeiro, Rio de Janeiro: ANPAD.

Chun, S-H. (2019). E-Commerce Liability and Security Breaches in Mobile Payment for eBusiness Sustainability. Sustainability, v. 11, p. 1-18.

Dahlberg, T., Guo, J. \& Ondrus, J. (2015). A critical review of mobile payment research. Electronic Commerce Research and Applications, v. 14, n. 5, p. 265-284.

Dewan, S \& Chen, L. (2005). Mobile Payment Adoption in the US: A Cross-Industry, CrossPlatform Solution. Journal of Information Privacy and Security, v. 1, n. 2, p. 4-28.

Diniz, E. H., Albuquerque, J. P. de. \& Cernev, A. K. (2011) Mobile money and payment: A literature review based on academic and practitioner-oriented publications (2001-2011). Proceedings of SIG GlobDev Fourth Annual Workshop, Shanghai, China.

Martins, G. S., Santos, C. A., Di Serio, L. C., Martins, M. E. (2008). Mobile Payment: Competitividade da Tecnologia de Pagamento via Telefonia Celular na Cadeia Brasileira de Cartão de Crédito. In: XXXII Encontro da Associação Nacional dos Cursos de PósGraduação em Administração, 2008, Rio de Janeiro, RJ. Anais do XXXII Encontro da Associação Nacional dos Cursos de Pós-Graduação em Administração. Rio de Janeiro, Rio de Janeiro: ANPAD.

Moretti, J. (2013). O que o Mobile Payment trará de novo no Brasil?

Código Fonte. Tecnologia [a-Z]. Disponível em http://codigofonte.uol.com.br/artigos/o-queo-mobile-payment-trara-de-novo-no-brasil Acesso em 01 jan. 2016.

Oliveira, T., Thomas, M., Baptista, G., Campos, F. (2016). Mobile payment: Understanding the determinants of customer adoption and intention to recommend the technology. Computers in Human Behavior, v. 61, p. 404-414.

Park, J. K., Ahn, J., Thavisay, T. \& Ren, T. (2019). Examining the role of anxiety and social influence in multi-benefits of mobile payment services. Journal of Retailing and Consumer Services, v. 47, p. 140-149. 
Ricardo, S. C. \& Freitas, H. M. R. (2015). O sistema de mobile payment no transporte público na cidade de São Paulo. In: IV Simpósio Internacional de Gestão de Projetos, Inovação e Sustentabilidade, São Paulo, SP.

Wang, G., Putri, N. M., Christianto, A. \& Hutama, D. (2019). An empirical examination of characteristics of mobile payment users in Indonesia. Journal of Theoretical and Applied Information Technology, v. 96, n. 1, p. 169-182. 